\title{
Rule-Based Design, in Honour of Lionel March
}

\author{
Mine Özkar ${ }^{1}$
}

Published online: 13 October 2015

(C) Kim Williams Books, Turin 2015

Design rules are directives that guide the design process towards the product. They are often specific descriptions of decisions and acts, which, taken as a whole, make up a design. Sometimes numeric, sometimes verbal, and most often visual or spatial, these descriptions have formed the core of analyses and recreations of design thinking since early history, with the most recent connotations arising in design computing. This issue of the Network Nexus Journal is dedicated to Lionel March, whose seminal contributions to computational art, architecture and design have profoundly influenced our understanding of creative thinking since the 1970s.

As the preparations ensued for the tenth Nexus conference "Nexus 2014: Relationships between Architecture and Mathematics" (Ankara, 2014), it was decided that one of the sessions, Rule-Based Design, was to celebrate the legacy of Lionel March in the year of his 80th birthday. Four of the papers presented in that session in Ankara have found their way to this special issue. When Lionel could not attend the conference personally, Kim Williams and I pursued the idea of a celebration in other forms. I am grateful to Kim, who then invited me to guest edit this issue and gave me the chance to bring together texts by prominent scholars of computational design and architecture with much appreciation for Lionel's presence in the field.

In line with the breadth of the impact that Lionel March has had in the field, the issue offers fourteen texts on a variety of topics and approaches of research. Seven of the papers focus on design ontologies, typologies, generative specifications and generating designs that range in scale from the city to furniture. Nine of the papers, some overlapping with the above seven, either directly focus or refer to shape grammars, a computational theory of shapes and visual thinking in design. Among

Mine Özkar

ozkar@itu.edu.tr

1 Mimarlık Bölümü Taşkışla, Mimarlık Fakültesi, Istanbul Teknik Üniversitesi, 34437

Taksim-Istanbul, Turkey 
these a few focus on the mathematics of implementing shape grammars, and two on their relation to calculating with physical things.

One paper that falls outside of the two categories above is "Leon Battista Alberti as Author of Hypnerotomachia Poliphili" by Lionel March. March goes back in history to the age of Renaissance in Italy to investigate a particular authorship based on clues of codes in numbers and letters. One of the most interesting early printed books, Hypnerotomachia Poliphili is an allegorical text of a romance and is usually credited to a Francesco Colonna. Referring to Leon Battista Alberti's cryptography, March illustrates that the design of the book is overlaid with codes and argues that the skill displayed in the book in coding with numbers is a clue for the Renaissance architect's authorship of the text.

The paper "The Critic as Artist: Oscar Wilde's Prolegomena to Shape Grammars" by George Stiny serves as an introductory discussion and a theoretical background for the other eight papers of the issue that refer to shape grammars. With a play on Oscar Wilde's words, Stiny explains that calculating is seeing and remarks "the importance of calculating without symbols". The critic, according to Wilde's aesthetic method, is expected "to see the object as in itself it really is not", whereas Stiny similarly values the artist for being open to "surprises" of seeing. In shape grammars (the artist's) rules are shape rules and allow for these surprises.

The six papers that follow illustrate analyses of designs at various scales ranging from the city to architectural elements and even to furniture, deciphering rules and types that these rules produce. These papers offer new tools for designers, most for working with historical contexts. In "Architectural Doughnuts: Circular-Plan Buildings, with and without Courtyards", Philip Steadman identifies throughout history some types of "doughnut plans" with thoughtful consideration of their functional differences (such as patterns of visibility). Steadman pays homage to work done by Lionel March and Leslie Martin in the 1970s on investigating the geometrical effects of placing buildings in peripheries of sites. Showing the numerical relations between various examples of circular plans, Steadman introduces the device of morphospace to guide designers' choices. Similarly, in "Typological Descriptions as Generative Guides for Historical Architecture", presented at Nexus 2014, Rudi Stouffs and Bige Tunçer examine a family of designs, specifically those of the classical period Ottoman mosques by the architect Sinan. In their ontological approach, which balances completeness and flexibility, they decompose the mosques, hierarchically arrange the components, and then parametrically describe the Sinan mosque as a type. The description grammar they offer for ontological typologies is also a generative mechanism. They illustrate this by generating limited aspects of an instance of the said typology. Another paper that accounts for generating new instances of historical designs is Rongrong $\mathrm{Yu}$, Michael J. Ostwald and Ning Gu's "Parametrically Generating New Instances of Traditional Chinese Private Gardens that Replicate Selected Socio-Spatial and Aesthetic Properties". Using space syntax methods, the authors mathematically derive the socio-spatial characteristics of historic Chinese private gardens and utilize the data to develop a parametric system to generate new plans with similar values. Finally, through fractal analysis, they compare the characteristics of the new and old plans. In "Competition in the Built Environment: Scaling Laws for Cities, 
Neighbourhoods and Buildings", Michael Batty illustrates that scaling, the theory behind size distributions in urban settings, specifically high buildings, impacts the quality of forms due to changes in forces. He catalogues a variety of applications of scaling and emphasizes that policymaking and planning can be more effective ways to implement scaling compared to how it is usually done through design. In "Generating a Visual Language of Performance-Driven Configurations for the Principal Façade of a Prototype Sustainable House", Sotirios Kotsopoulos develops a performance-driven application of shape grammars and illustrates how this parametric shape grammar generates patterns for a façade of electrochromic windows. In "A Grammar-Based Model for the Mass Customisation of Chairs: Modelling the Optimisation Part", another shape grammar application, authors Mário Barros, José Pinto Duarte and B. M. Chaparro propose a method for generating forms and evaluating the optimized structural feasibility of these forms as they contribute to the transition from mass production to mass customization in the furniture industry, as illustrated in their explorations of Thonet bentwood chair designs.

The next two papers focus on the mathematics of certain forms used in designs. In "Pinwheel Patterns: From 2D to 3D Schemas", presented at Nexus 2014, Christopher F. Earl and Iestyn Jowers examine pinwheels-a common schema both in 2D and 3D form in architecture and design - to offer a generative description utilizing shape computation methodology. Theirs is another paper intended to offer a guide for designers. Their approach can be generalized to analyses of other types of compositions, especially those in design education or analysis of form. In "Is the List of Incomplete Open Cubes Complete?" Natasha Rozhkovskaya and Michael Reb present detective work on Sol LeWitt's "Variations of Incomplete Open Cubes" and through an algorithmic check of the enumerated list of the cubes reveal a small mistake by the artist. Moreover, the authors' graph-based method visually befits the problem very well! A detail from the paper appears on the cover of this issue.

The two papers that follow relate to shape grammars from a theoretical perspective. In "Mulling Over Shapes, Rules and Numbers" Ramesh Krishnamurti addresses a fundamental question whether "forms produced by digital means are really radically distinct from those drawn by hand". His answer is neither complete nor intended to be, but as he discusses shapes, geometry and numeric encodings, Krishnamurti leads us through digital and analog ways of constructing shapes. Iestyn Jowers and Christopher F. Earl's "Extending the Algebras of Design", presented at Nexus 2014, points out that shapes composed of curves, surfaces or solids are usually left out in applications of shape algebras. Bearing similarities with Stiny's and Krishnamurti's papers in terms of the emphasis put on the concept of embedding (part relation), this paper inquires into the complications of formalizing embedding, whether it is analytical, visual, or both, and discusses the analytic and visual options for further development of the existing framework for shape algebras to include curved shapes.

The final research paper in this issue, "Shapes and Other Things" by Terry Knight is in a similar spirit for extending shape grammar applications and accounts for things with material properties in addition to shapes. Terry Knight offers a 
timely review of the history of shape grammars with a focus on dealings with materials and physical things. Claiming that designing is also making, Knight argues for a new approach and adapts shape grammars to define making grammars for things. Finally, the issue concludes with the Didactics section. "Schematizing Basic Design in Ilhan Koman's 'Embryonic' Approach" by Benay Gürsoy and myself, presented at Nexus 2014, reports on a design teaching method based on an analysis of a series of abstract works by Ilhan Koman, an artist with a deep interest in mathematics. The mathematical concepts in his approach are represented in visual schemas which act as guides and constraints to first-year design students striving to establish an understanding of how to design.

The four papers that were originally presented at the 2014 Nexus Conference in Ankara went through a double-blind-refereeing process prior to acceptance and presentation, and gained from discussions at the conference. The remainder of the papers arrived through the conventional journal process upon invitation and underwent the same blind peer review by experts.

It is a great pleasure, honour and privilege to be the guest editor of this really special and memorable issue. Lionel March has been an inspiration for many, and the Nexus Network Journal is pleased to dedicate this issue to him.

Mine Özkar is an associate professor of architecture at Istanbul Technical University, where she is the coordinator of the Program in Computational Design. She teaches graduate level design research methods, a computational design studio, several computational theory courses and an undergraduate architectural design studio. She earned her MS in design inquiry and PhD in design and computation from MIT. In some of her previous work, she has interpreted the history and theory of progressive pedagogy in art and design from a computational perspective. Her current research focuses on shape representation for creative computing, visual/spatial computation, and design methods as well as the integration of foundational design education and computational knowledge. She also publishes on the on-going global and local curriculum reforms in architectural education. She recently co-edited a book entitled Shaping Design Teaching and was a Visiting Professor in the MIT Department of Architecture Computation Group during Spring term of 2013. 